\title{
LA CITÉ DES DAMES: UTOPIA E GÊNERO
}

\section{Luciana Eleonora de F. Calado*}

Resumo: Caracterizada como um período de intensa repressão feminina, a Idade Média representa também uma época de contestações, em particular na vida literária, seja com a expansão do gênero poético conhecido como "Cantiga de Amigo" (Chanson de Femme, Frauenlied), que consiste na expressão dos sentimentos através de um eu-lírico feminino, seja com a própria produção de mulheres, as chamadas trobairitz. Dentre estas, a escritora do século XIV Christine de Pizan é o nome mais notável, menos pela sua vasta e variada produção poética e prosaica, mas especialmente pela ousadia em deslocar o papel da mulher nos escritos da época - na sua grande maioria, misóginos - em sentido de uma abordagem feminista questionadora da "natural" superioridade masculina. Neste artigo, pretendese analisar uma das mais importantes obras de Christine de Pizan, La Cité des Dames (A cidade das damas), enfocando a imagem do feminino e o plano utópico desta "cidade metafórica".

Palavras-chave: Utopia. Literatura Medieval. Gênero. Christine de Pizan. La Cité des Dames.

...voici notre Cité bâtie et parachevée. Vous toutes qui aimez la vertu, la gloire et la renommée y serez accueillies dans les plus grands honneurs, (...) si vous en prenez soin, sera pour vous toutes (c'est-à-dire les femmes de bien) non seulement un refuge, mais un rempart pour vous defendre des attaques de vos ennemis...

\section{Christine de Pizan, La Cité des Dames.}

Desejar o impossível, fazer o impossível: tal foi o caminho perseguido por Christine de Pizan, na construção de uma obra e vida

- Doutoranda em Teoria Literária do Programa de Pós-Graduação em Letras da Universidade Federal de Pernambuco, com estágio doutoral na Université Blaise-Pascal, em Clermont-Ferrand - França. 
tão singulares, tão fora de lugar, tão utópicas. Essa escritora do século XIV transformou traços de sua vida, que a colocariam naturalmente em desvantagem (mulher, viúva, estrangeira) ${ }^{1}$, em armas eficazes, por meio das quais ascende a uma condição até então inatingida pelas mulheres: a conquista de ser a primeira mulher a sobreviver do ofício de escritora.

Sua vida confunde-se, de certa forma, com a sua obra, na medida em que se vêem refletidas, na sua extensa produção literária, as imposições, injustiças e ataques misóginos, que seguramente deve ter enfrentado, tão característicos daquela sociedade patriarcal. Christine de Pizan bate-se, portanto, em defesa de uma sociedade diferente para as mulheres, de um mundo utópico, projetado no livro: La Cité des Dames (2000).

Os estudos sobre as obras medievais - carregadas da dualidade platônica entre o bem/o mal, o belo/o feio, o sagrado/o profano - sempre as direcionaram (acredito, com razão) para o eterno embate entre defesa e recusa da realidade existente. Assim, de um lado, em defesa daquele modelo hierárquico vigente, conhecemos muito bem a imensidão de obras que foram e são até hoje responsáveis pela real e imaginária formação da "era das trevas", sempre estando transparentes no clarão da visibilidade. De um outro lado, bem mais encobertos, com pouca luz e condenados muitas vezes literalmente ao "inferno", encontram-se os livros que questionavam, que tentavam ofuscar as idéias tão costumeiramente estáticas, obscuras, por permanecerem confinadas às sombrias cortes, catedrais, e por não conseguirem reter a luz que se refletia do lado de fora dessas instituições, bem além dos imensos portais e janelas.

A tarefa de des-velar (do latim velum = véu), de vasculhar, essas obras pouco conhecidas ficou para nossa era moderna, ou pós-

Christine de Pizan (1364-1430), filha de italianos, nasceu na Itália, chegando só aos quatro anos à França, onde permaneceu até sua morte. (Cf. entre outras referências bibliográficas: LÉON, Vicki. Mulheres audaciosas da Idade Média. Tradução de Marita Fornos de Magalhães. Rio de Janeiro: Rosa dos Tempos, 1998; Dictionnaire des lettres françaises: Le Moyen Âge. Ouvrage préparé par Robert Bossuat, Louis Pichard et Guy Raynaud de Lage. Paris: Fayard, 1964). 
moderna. Era do neo, do menor, do periférico, do híbrido, do contra. É essa atmosfera de inclinação ao alter que dá lugar ao interesse pela literatura medieval, por escritas de contestação, de recusa à ordem estabelecida, fossem elas de caráter moral, identificadas nas abordagens irônicas ou moralistas contra vícios 'anticorteses' da sociedade (como a avareza, a hipocrisia, a arrogância), fossem de caráter político-econômico-social, com registros de fatos sociais marcantes, em particular as cruzadas e as perseguições aos movimentos heréticos, fossem ainda de caráter utópico, como as lendas do "país da Cocanha", com versões em várias línguas vernáculas européias, o Livre de la Cité des Dames, da escritora Christine de Pizan e outros. É particularmente esta última obra, do final da Idade Média, que será trazida como objeto desta análise sobre o ideal feminino e o caráter utópico da obra.

Para abordar a questão da utopia, serão lembradas as três funções dessa categoria apontadas pelo filósofo Ernst Bloch (1976): a transgressão da situação presente, desmascarando o lado sombrio da ordem estabelecida; um deslocamento do presente real para o futuro imaginário, através de transformações da realidade existente; e, por último, a recusa da idéia de conformismo e fatalismo sob a forma de uma "atualização do desejo", na atuação da esperança.

\section{Tirando a máscara}

O desmascaramento da realidade existente pode ser visto na obra de Christine de Pizan como um dos seus principais aspectos, na medida em que ela se constitui basicamente de um jogo de indagações e respostas entre a personagem-narradora Christine e as três damas alegóricas: Razão, Retidão e Justiça, a respeito das características e concepções de feminino que habitam o pensamento daquela sociedade. Os questionamentos podem ser lidos como denúncias da situação feminina na época, levantando problemas graves, como a violação da mulher, a dominação mascuĩina, as acusações misóginas da inferioridade feminina em três níveis: intelectual, físico e moral, na tentativa de justificar e perpetuar tal dominação.

Essas acusações são desmascaradas através de um criterioso levantamento histórico de exemplos femininos de conduta e atuação, desde a Antiguiidade clássica, destacando as virtudes das Amazonas, 
das Deusas da Mitologia grega, até a sua contemporaneidade. Dando prova de uma grande erudição, Christine de Pizan inclui-se também nos exemplos, a fim de demonstrar metalingüisticamente a igualdade intelectual entre os sexos. Em uma fala da Senhora Razão, ${ }^{2}$ respondendo-lhe sobre a pretensa inferioridade dos conhecimentos femininos, Christine trata de socializar que o saber é uma questão de oportunidade, não de sexo:

C'est sans aucun doute qu'elles n'ont pas l'expérience de tant de choses différentes, mais, s'en tenant aux soins du ménage, elles restent chez elles, et rien n'est aussi stimulant pour un être doué de raison qu'une expérience riche et variée [...] pense donc aux habitants des campagnes reculées ou des hauts plateaux; tu m'accorderas que dans plusieurs pays ils sont si simples qu'on les prendrait pour des bêtes. Et pourtant il est incontestable que Nature les a pourvus de tous les dons physiques et intellectuels qu'elle offre aux hommes les plus sages et les plus érudits que l'on puísse trouver dans nos capitales et grandes villes (PIZAN, 2000, p. 92). ${ }^{3}$

A tal falta de oportunidade, a inacessibilidade das mulheres às Universidades - eis o que faz gerar uma literatura quase que exclusivamente masculina: feita por homens, para homens e contra

2 Convém lembrar, a propósito desse estranho tratamento "senhorial" dispensado às virtudes, que não era propriamente atípico na literatura da época. Antes de Pizan, já no século XII, os escritos de Francisco de Assis se acham repletos de reverência ao "Senhor" Sol, à "Senhora" Lua, à "Senhora" Pobreza, etc. Também a alegoria era uma constante naquela literatura.

3 "É sem dúvida alguma que elas não têm experiência de tantas coisas diferentes, mas, se aplicando às tarefas domésticas, ficam $\mathrm{em}$ casa, e nada é mais estimulante para um ser dotado de razão do que uma experiência rica e variada [...] pense, pois, nos habitantes de sítios afastados ou de serras altas; você concordará comigo que em muitos países eles são tão simples que passariam por animais. E, no entanto, é incontestável que Natureza os proveu de todos os dons físicos e intelectuais oferecidos aos homens mais sábios e eruditos que se possa encontrar nas nossas capitais e cidades grandes". Todas as traduções do francês são de minha autoria. 
mulheres. Dentre as obras citadas, Christine de Pizan chama a atenção para cânones da Antigüidade e da Idade Média que, a despeito do seu valor estético, apresentam uma imagem feminina deformadora e preconceituosa. Vejamos a indignação da narradora face à notável presença de idéias misóginas em grandes clássicos da literatura ocidental, como $A$ arte de amar, de Ovídio, e a segunda parte de Le Roman de la Rose, de Jean de Meun:

Ma Dame, comment Ovide - que l'on dit pourtant Prince des poètes, bien que certains, dont je suis, estiment que la palme revient - plutôt à Virgile (sauf correction de votre part)-, a-t-il pu dire tant de mal des femmes dans sés poèmes: dans l'ouvrage intitule 'L'Art d'aimer', par exemple, ou bien encore dans "Les Remèdes d'amour", ou bien d'autres ouvrages encore? ((PIZAN, 2000, p. 52). ${ }^{4}$

[...] je m’étonne tant de cette opinion -assez répandue parmi les hommes (Jean de Meun en particulier le clame bien haut dans son Roman de la Rose, et il est loin d'être le Seul auteur à le faire) - que les maris doivent se garder de confier leurs secrets à leurs épouses, car les femmes sont incapables de se taire (PIZAN, 2000, p.: 161) ${ }^{5}$.

A responsabilidade pela difusão dessa cultura misógina na literatura é explicada pelo fato de os escritos pertencerem ao império masculino na sua quase totalidade. Assim, suas obras refletem uma ideologia, obviamente, masculina. Pois, na medida em que a classe dominante é a dos homens, a mentalidade que reina, conseqüentemente, será também a patriarcal.

4 "Minha Dama, como Ovídio - que dizem ser o Príncipe dos poetas [...] pôde falar tão mal das mulheres em seus poemas: na obra intitulada 'A Arte de amar', por exemplo, ou ainda em 'Os Remédios de amar', ou em tantas outras obras ainda?".

5 "[...] surpreende-me esta opinião - bastante difundida entre os homens (Jean de Meun em particular a clama bem alto em seu 'Roman de la Rose', e está longe de ser o único a fazê-lo) - que os maridos devam se resguardar de confiar seus segredos a suas esposas, pois as mulheres são incapazes de calarem-se." 
Esse império masculino estaria na origem de injustiças frente à mulher, denunciadas lucidamente em várias passagens do texto, onde a autora, na voz da senhora Retidão, faz apelo ao saber empírico, ao cotidiano, à própria experiência das mulheres para resumir o quadro da realidade feminina:

Ah! chère Christine! Tu sais toi-même combien de femmes on peut voir, par la faute d'un mari cruel, user leur malheureuse vie dans les chaînes d'un mariage où elles sont encore plus maltraitées que les esclaves des Sarrasins. Ah! Seigneur! [...] Oh! Les indignités, les infamies, les injures, offenses et outrages qu'endurent tant de bonnes et valeureuses femmes, sans la moindre protestation. Et combiens d'autres, encore, chargées d'une nombreuse progéniture, ne voit-on pas creuver la faim et la misère, alors que leurs maris traînent dans les lieux de débauche et font la noce dans toutes les tevernes de la ville! [...]. Dis-moi si je mens, et si tel n'est pas le lot de plusieurs de tes voisines? (PIZAN, 2000, p. 146) ${ }^{6}$.

Essa relação de poder, do dominador versus dominado, se fortalece e se mantém viva através do domínio do saber, numa concepção foucaultiana em que o poder se equipare ao saber (Cf. FOUCAULT, 1993), o que vai justificar a necessidade de se privar a mulher do acesso ao saber como ameaça ao império masculino:

C'est un fait que tous les hommes, et en particulier ceux parmi eux qui sont les plus instruits, ne partagent pas l'opinion evoqué plus haut [que la connaissance ne corrompe pas les femmes], et qui voudrait que

"Ah! Cara Cristina! Você mesma sabe quantas mulheres podemos ver, por conta de um marido cruel, estragarem sua vida infeliz num casamento de prisão, onde elas são ainda mais maltratadas do que os escravos dos sarracenos. Ah! Senhor! Oh! As indignidades, as infâmias, as injúrias, ofensas e afrontas às quais tantas mulheres boas e de valor são submetidas, sem o menor protesto. E, quantas outras, ainda, carregadas de uma numerosa prole, vivem com fome e na miséria, enquanto seus maridos vagueiam em lugares depravados, levando essa vida de promiscuidade em todas as tabernas da cidade! [...] Diga-me se estou mentindo, e se tal não é a sorte de várias de suas vizinhas?" 
l'éducation des femmes soit un mal. Il est bien vrai cependant que parmi les moins instruits bon nombre y souscrivent, car il leur déplairait que des femmes soient plus savantes qu'eux (PIZAN, 2000, p. 106) ${ }^{7}$.

A conjuntura social à qual recorre a autora marca o primeiro passo na busca de uma realidade idealizada na busca de uma Utopia, evocando, no livro, discussões, questionamentos que se contrapõem àquela realidade imposta.

Desconcertando o real, rumo a um novo imaginário

O livro La cité des dames é acima de tudo uma verdadeira enciclopédia das mulheres, um resgate de várias personagens femininas, da história à mitologia, da Antiguidade à Idade Média, das letras às ciências, destacando nelas, ora suas qualidades pretensamente masculinas, como a coragem, a ousadia, a bravura, seus feitos históricos, ora suas qualidades reconhecidas como femininas, como a sensibilidade, a dedicação, a solidariedade. O texto tem ainda o poder de transformar em virtudes características que muitas vezes lhes serviram de motivos para ataques irônicos, como: a facilidade do choro, ou ainda a fragilidade de seus corpos (que, numa visão aristotélica, as tornaria mais debilitadas, mais imperfeitas em relação aos homens) e, dentre outras, a semelhança, em termos de ignorância, às crianças. Face à indignação da personagem Christine diante do provérbio latino " $\mathrm{C}$ 'est pour pleurer, parler et filer, que Dieu créa la femme", a Senhora Razão lhe responde surpreendentemente, dandolhe legitimidade: "ce dicton est vrai. Mais, quoi que l'on pense ou dise, il n'y a là aucun motif de reproche. C'est une excellente chose

7 "É fato que todos os homens, e em particular os que dentre eles são mais instruídos, não dividem a opinião evocada acima [de que o conhecimento não corrompe as mulheres], e que pretendem que a educação das mulheres seja um mal. É bem verdade no entanto que entre os mais instruídos um bom número assina embaixo, pois desagradaria que as mulheres fossem mais sábias do que eles."

8 "Deus criou a mulher para chorar, falar e tecer." 
que Dieu les ait donné une telle vocation, car beaucoup ont été sauvées par pleurs, quenouilles et paroles" (PIZAN, 2000, p. 58) ${ }^{9}$.

Os considerados defeitos tornam-se, então, virtudes, nos argumentos da escritora. Nessa medida, o choro, de fraqueza torna-se arma, como nos muitos exemplos em que a salvação de pessoas pelas lágrimas é mostrada, como Maria Madalena, perdoada de seus pecados e aceita no reino dos céus pelo seu choro; o seu irmão Lázaro, cuja ressurreição se deu pela compaixão de Jesus pelas lágrimas das irmãs Marta e Maria Madalena. Quanto à fala das mulheres, a Senhora Razão avalia que,"si parole de femme eût été si condamnable et de si peu d'autorité que le prétendent certains, Notre-Seigneur Jésus-Christ n'eût jamais daigné qu'une femme annonçât la première le mystère si glorieux de sa Réssurrection" (PIZAN, 2000, p. 60). ${ }^{10}$

Uma outra questão que pretende contrariar o senso comum em relação às características femininas é o da referida aproximação das mulheres com as crianças, dada a equiparável leviandade e ignorância, que as levariam, na prática, a um plano inferior e negligenciável em relação aos homens.

Sobre a ligação das mulheres com as crianças, Senhora Razão traz o seguinte argumento:

Ah! Voyez la perversité de ces gens diaboliques qui veulent faire de Douceur, ce bien et cette vertu que Nature accorde aux femmes, un vice et un reproche! $\mathrm{Ce}$ $n^{\prime}$ est pas parce que les femmes sont ignorantes qu'elles aiment les enfants; cela provient, au contraire, de leur bonté naturelle. Et si, comme les enfants, elles sont douces, il faut admettre qu’elles en sont parfaitement

9 "Esse ditado é verdadeiro. Mas, apesar do que se pensa ou se diga, não há nenhum motivo para reprová-lo. Foi excelente Deus ter lhes dado tal ocação, pois quantos não foram salvos pelas palavras, pelo chorar e pelo tecer dessas mulheres."

10 "Se a fala da mulher fosse tão reprovável e de tão pouca autoridade como sustentam alguns, Nosso Senhor Jesus Cristo não teria consentido que fosse uma mulher a primeira pessoa a anunciar o tão grande mistério como o da sua gloriosa Ressurreição." 
bien avisées. L'Évangile nous rapelle que lorsque les apôtres se disputaient pour savoir qui d'entre eux serait le plus grand, Notre-Seigneur prit un enfant et, posant la main sur la tête de celui-ci, leur dit: 'Je vous le dis, quiconque restera humble et petit comme cet enfant, sera le plus exalté. Car quiconque s'élève sera abaissé, et celui qui s'abaisse sera elevé.' (PIZAN, 2000, p. 60). ${ }^{11}$

Ainda que com a carga impregnada de fundamentação bíblica na construção do logos em seu processo retórico, o livro La Cité des Dames levanta uma questão não usual para a época, reivindicando uma outra postura em relação à situação das crianças, que só será objeto de discussão no século XIX, com as consequiências trazidas pela Revolução Industrial para o seio familiar.

Se, de um lado, a autora refuta, com todos os seus processos retóricos, aquela imagem feminina, criada e em expansão naquela sociedade misógina, por outro lado, e, simultaneamente, ela vai dando contornos a uma nova concepção do feminino e desconstruindo a imagem sagrada do masculino.

Para tanto, a autora, num primeiro momento, revida os ataques misóginos difundidos nas obras da época, justificando com a citação de uma série de homens da História que dão prova de covardia, fraqueza, ao mesmo tempo em que resgata as mulheres de força, coragem, inteligência. Em seguida, ela abre espaço para uma outra discussão, a questão do feminino / masculino como condição do ser humano. Nesse caminho, são levantados vários exemplos de falhas e virtudes recíprocas, prova da complexidade e imperfeição da própria

11 "Ah! Vejam a perversidade dessas pessoas diabólicas que querem fazer da Doçura, este bem e virtude que a Natureza acordou às mulheres, um vício e uma repreensão! Não é porque as mulheres são ignorantes que elas gostam das crianças; isso provém, ao contrário, de sua natural bondade. E se, como as crianças, elas são doces, é preciso admitir que agem perfeitamente com muita reflexão. O Evangelho nos ensina que enquanto os apóstolos disputavam entre si para saber quem dentre eles seria o maior, Nosso-Senhor tomou uma criança, e colocando a mão sobre sua cabeça, disse-lhes: 'Vos digo: Aquele que ficará humilde e pequeno como essa criança será o mais exaltado. Pois aquele que se exalta será rebaixado, e aquele que se rebaixa será elevado'." 
condição humana. Num tom irônico, a voz da Senhora Retidão traz a seguinte reflexão: "Quand les hommes seront parfaits, alors les femmes les imiteront!" (PIZAN, 2000, p. 210). ${ }^{12}$

\section{Atualização dos desejos: esperança de um bonum futurum}

Essa transformação de pontos de vista e esse deslocamento de ângulo de percepção culminam com a idéia de construção de uma nova realidade, a construção de uma cidade, de uma fortaleza que teria o objetivo de defender as mulheres dessa sociedade misógina. Tal fortaleza, escolhida para ser fixada em um lugar rico e fértil, no "Campo das Letras", confunde-se metaforicamente com o próprio livro, que pretendia ter esse mesmo objetivo, o de proteger as mulheres das injustiças das quais eram vítimas.

A construção de uma cidade utópica para as mulheres representa o símbolo de recusa ao conformismo, e a expressão da vontade de mudança, rumo a uma nova era: "Voici donc que s'ouvre l'ère d'un nouveau royaume de Féminie" (PIZAN, 2000, p. 144). ${ }^{13}$ Bloch associa à atividade da "consciência antecipadora". Essa tal consciência é que levaria, em oposição ao sentimento negativo de temor (relacionado a um malum futurum), à esperança e à crença em um bonum futurum (MÜNSTER, 1993).

A obra La Cité des Dames é também uma recusa ao passado, às tentativas masculinas, para Christine de Pizan, mal sucedidas de mundos utópicos, como a cidade de Tróia, fundada com a ajuda de Apolo, Minerva e Netuno, a cidade de Thebas, fundada por Cadmus sob a injunção divina, cidades que, com o tempo, desmoronaram, tombadas em ruínas, como também construções femininas, como o reino das Amazonas que, apesar de toda força e ousadia, terminou por terra.

Contrariamente aos edifícios anteriores, ${ }^{14}$ a Cité des Dames pretende ser "bien plus parfait que celui de jadis", uma obra que,

12 "Quando os homens forem perfeitos, então as mulheres os imitarão!"

13 "Eis que se inicia o novo reinado Feminino."

14 Curioso observar que Pizan, embora tendo citado a poetisa grega, Safo, como "uma mulher de grande genialidade, poetisa e filósofa", não faz nenhuma referência à capital da ilha de Lesbos, Mitilene, onde Safo 
graças ao material com o qual foi alicerçada, da mais durabilidade, nobreza, e beleza, poderia ter permanência eterna neste mundo.

A ênfase na durabilidade dessa obra, o desejo de divulgação e utilidade para as mulheres, parece nascer de uma idéia visionária de que tal situação vigente permaneceria ainda por tempos indeterminados, como realmente aconteceu. A prova é que várias reivindicações levantadas no livro - como o acesso da mulher ao saber, a igualdade entre os sexos, a questão da violência física contra a mulher - continuam válidas, sete séculos depois, apesar do grande avanço do movimento feminista, nas nossas pautas de discussões em uma decepcionante atualidade.

A cidade das mulheres representa, pois, a apreensão da realidade como produto da imaginação, uma res ficta ("coisa imaginada"), onde, através do discurso, Christine de Pizan transporta seus sonhos - e por extensão, os ideais de todo um grupo social -, da realidade concreta para a realidade imaginária.

A presença de um exclusivo universo feminino na idealização, na construção e no povoamento da cidade, a valorização das virtudes e traços característicos da mulher, a suspensão do fluir do tempo e do espaço único, reunindo mulheres guerreiras do passado, presente e futuro em um mesmo lugar, em suma, a presença de todos esses elementos imaginários nessa narrativa medieval funciona como crítica

fundou a Residência das Discípulas das Musas, uma espécie de confraria, universidade, academia, conservatório feminino de arte, dedicado às Musas e à deusa Afrodite, onde se ensinavam dança, música instrumental, canto, poesia e o culto do físico. Analisando a importância de tal construção, Junito Brandão (1989, p. 19) faz o seguinte comentário: "Para um "país" como a Grécia, em que a mulher, semi-analfabeta, passava o tempo no gineceu ocupando-se do tear e da roca, a Residência das Discípulas das Musas foi uma iniciativa corajosa e arrojada." A ausência dessa iniciativa na obra de Pizan, como exemplo de espaço idealizado, pode ser interpretada como conseqüência da sua pouca valorização dos rituais mundanos, de culto ao corpo, deixando explícita em várias passagens sua preferência pelas qualidades morais, pelo espírito. Na obra de Christine de Pizan, como em qualquer obra humana, encontra-se o seu fator ideológico, reafirmando a máxima: "Quem escreve, inscreve-se". 
social, agressão ao status quo, negação dos valores misóginos da época e, sobretudo, como a utopia feminina do século XV.

Referências

BRANDÃO, Junito de S. Helena: o eterno feminino. Rio de Janeiro: Vozes, 1989.

BLOCH, Ernst. Le Principe Espérance. Tome I. Traduit de l'allemand par Françoise Wuilmrt. Paris: Gallimard, 1976. Titre original: Das Prinzip Hoffnung. Frankfurt: Surhrkamp Verlag, 1959.

BOSSUAT, Robert; PICHARD, Louis; LAGE, Guy Raynaud de. Dictionnaire des lettres françaises: le Moyen Âge. Paris: Fayard, 1964.

FOUCAULT, Michel. Microfísica do poder. 11. ed. Rio de Janeiro: Graal, 1993.

HURBON, Laënnec. Ernst Bloch: utopie et espérance. Paris: Éditions du Cerf, 1974.

LÉON, Vicki. Mulheres audaciosas da Idade Média. Tradução Marita Fornos de Magalhães. Rio de Janeiro: Rosa dos Tempos, 1998.

MÜNSTER, Arno. Ernst Bloch: filosofia da práxis e utopia concreta. São Paulo: Editora da Universidade Estadual Paulista, 1993.

PIZAN, Christine de. La Cité des Dames. Texte traduit et presenté par Thérèse Moreau et Eric Hicks. 4. ed. Paris: Stock, 2000. 